\title{
Cross-Cultural Differences in Memory: The Role of Culture-Based Stereotypes About Aging
}

\author{
Carolyn Yoon \\ University of Michigan \\ Fred Feinberg \\ University of Michigan
}

\author{
Lynn Hasher \\ Duke University
}

Tamara A. Rahhal

University of Illinois at Urbana-Champaign

\author{
Gordon Winocur \\ Rotman Research Institute and Trent University
}

\begin{abstract}
The extent to which cultural stereotypes about aging contribute to age differences in memory performance is investigated by comparing younger and older Anglophone Canadians to demographically matched Chinese Canadians, who tend to hold more positive views of aging. Four memory tests were administered. In contrast to B. Levy and E. Langer's (1994) findings, younger adults in both cultural groups outperformed their older comparison group on all memory tests. For 2 tests, which made use of visual stimuli resembling ideographic characters in written Chinese, the older Chinese Canadians approached, but did not reach, the performance achieved by their younger counterparts, as well as outperformed the older Anglophone Canadians. However, on the other two tests, which assess memory for complex figures and abstract designs, no differences were observed between the older Chinese and Anglophone Canadians. Path analysis results suggest that this pattern of findings is not easily attributed to a wholly culturally based account of age differences in memory performance.
\end{abstract}

Cultures differ in the way in which aging is viewed. In mainstream North America, old age is generally regarded by both younger and older adults as a period of poor health, loneliness, resistance to change, and declining physical as well as mental abilities (Erber, 1989; Pratt \& Norris, 1994; Ryan, 1992). A number of researchers have suggested that such negative agebased stereotypes may have a detrimental impact on cognition and, especially, on memory as people age (Cavanaugh, 1989; Levy \& Langer, 1994; Ryan \& Kwong See, 1993). But, as in a number of Asian cultures, some groups in North America (e.g., American Sign Language speakers, Native American Indians, Hispanic Americans) hold more positive views of aging, and recent research

Carolyn Yoon and Fred Feinberg, University of Michigan Business School; Lynn Hasher, Department of Psychology: Social and Health Sciences, Duke University; Tamara A. Rahhal, Department of Psychology, University of Illinois at Urbana-Champaign; Gordon Winocur, Department of Psychology, Rotman Research Institute and Trent University.

This study was supported by a grant from the Social Sciences and Humanities Research Council of Canada and by Grants AG12753 and AG4306 from the National Institute on Aging. Much of the work was conducted while Carolyn Yoon and Fred Feinberg were at the University of Toronto. We wish to acknowledge the assistance of Jia Lin Xie, Michelle Lee, Vivien Choy, Stanley Wu, Pak Wai Ho, Tin Wing Lee, and Wirasneny Fangiono at various stages of this project.

Correspondence concerning this article should be addressed to Carolyn Yoon, University of Michigan Business School, 701 Tappan Street, Ann Arbor, Michigan 48109-1234. Electronic mail may be sent to yoonc@ umich.edu. by Levy and Langer (1994) suggests that such positive cultural views of aging may preserve memory performance among older adults. Although some empirical support for a culture-based explanation of widely observed age differences in memory has been found, other researchers have observed either a nonexistent or relatively weak relationship between older adults' self-perceptions related to aging and their memory performance (Kahn, Zarit, Hilbert, \& Niederehe, 1975; Scogin, Storandt, \& Lott, 1985). Given the equivocal nature of the evidence regarding the relationship between cultural stereotypes of aging and cognitive performance, a critical question is the degree to which cultural stereotypes contribute, if at all, to age differences in memory performance.

Although the predominant finding in the cognitive gerontology literature is that memory performance tends to decline as people age (Kausler, 1994; Zacks, Hasher, \& Li, 1999), some researchers have suggested that the decline may not be inevitable and can be influenced by older adults' stereotypically negative expectations about the aging process itself, as well as through reduced selfefficacy levels (e.g., Lachman, Weaver, Bandura, Elliott, \& Lewkowicz, 1992; Langer, Rodin, Beck, Weinman, \& Spitzer, 1979; Rodin \& Langer, 1980). Although the research on whether self-efficacy beliefs affect memory and cognition across the lifespan has sometimes produced mixed results, there is nonetheless empirical evidence to suggest that positive expectations may be related to enhanced cognitive performance and negative expectations to poorer cognitive performance (Albert, Jones, Savage, Berkman, Seeman, Blazer, \& Rowe, 1995; Hertzog, Dixon, \& Hultsch, 1990; Ryan, Kwong-See, Meneer, \& Trovato, 1992). 
The idea that older adults' performance on cognitively challenging tasks may be constrained by negative self-perceptions and enhanced by positive self-perceptions was examined by Levy (1996). In the first experiment conducted with older participants, Levy activated both negative (e.g., senile) and positive (e.g., wise) stereotypes of aging. Priming negative stereotypes led to poorer memory performance, whereas positive stereotypes resulted in enhanced performance. In a second experiment conducted with younger individuals, Levy found no such effects of positive or negative stereotypes of aging. On the basis of these results, Levy suggested that stereotypes can influence performance but are more likely to do so if they are relevant to an individual's self-image.

The extent to which cultural stereotypes about aging influence memory performance was directly investigated by Levy and Langer (1994). They asserted that in cultures where more positive views of the elderly predominate [e.g., Chinese and American Sign Language (ASL) communities], age-related decline in cognitive functioning may not be inevitable. To test this, Levy and Langer administered a series of four nonverbal memory tests to younger and older mainland Chinese hearing, ASL, and American-hearing individuals. Consistent with a stereotype interpretation, they confirmed that the Chinese-hearing and ASL participants did indeed view older people more positively than their American-hearing counterparts, and they found that age differences in performance were substantially reduced for these two groups relative to those for hearing Americans. Using a path analysis based on a combined memory score from the four tests as the dependent variable and views of aging and cultural membership as independent variables, they reported that, among the elderly, the influence of culture on memory performance is mediated by views of aging. On the basis of these findings, Levy and Langer suggested that more positive cultural beliefs about aging among the ASL and Chinese cultures account for the superior memory skills exhibited by older individuals from these communities compared with older Americanhearing adults.

The performance of older adults in the Levy and Langer (1994) study calls into question a predominant finding in the literature, that age differences in performance on deliberate memory tests do exist, thereby raising some doubt as to the robustness of a culturebased explanation. Further, several aspects of their study raise potential causes for concern. First, the critical conclusions drawn were based on limited samples of participants in each age by cultural group ( $n s=15$ ), such that the statistical power to detect true differences between the groups was limited. Second, although Levy and Langer (1994) included nonverbal memory tests that have been demonstrated to uncover age-related declines in memory among Westerners, it is unclear how culturally invariant these tests are when applied to younger and older Chinese samples. For instance, one of the four memory tasks utilized by Levy and Langer (1994) involved presenting participants with photographed faces of older individuals matched with activities, followed by a probed recall test in which participants were shown the photographs and asked to recall the associated activity. This is of concern insofar as the participants' performance on the task draws on memory for configural properties of faces. We suggest the possibility that high performance on such a task may differentially draw on a processing orientation favored by the Chinese samples, thereby potentially obscuring any age-related variation in performance for the two cultural groups across different memory tests.
There is now mounting evidence that, compared with their Western counterparts, the Chinese individuals are especially sensitive to contextual relationships and have a tendency to process information holistically (Fiske, Kitayama, Markus, \& Nisbett, 1998). Park, Nisbett, and Hedden (1999) have recently suggested that this cultural predilection for holistic processing may be an automatically activated tendency requiring few resources, especially in the presence of informational stimuli that lend themselves to this type of processing. To the extent that cultural bias for holistic processing remains well-preserved across the lifespan among the Chinese, we might thus expect smaller decrements in performance, compared with Americans, on memory tests such as the probed recall test used by Levy and Langer (1994). Moreover, the three other tests utilized by Levy and Langer (1994) involved memorization of the same four configurations of seven dots across different time intervals. Because only a composite memory score was derived (from the four memory tests) and reported in the study, their memory data are difficult to evaluate.

Finally, although any comparison between the studies is complicated by the fact that only an overall memory score (a combination of measures from four memory tests) is reported for the Levy and Langer (1994) study, whereas scores on seven separate memory tests are reported by Levy (1996), the pattern of results found in the Levy and Langer (1994) study appears not to be replicated by Levy (1996). That is, comparing across Levy's (1996) Experiments 1 and 2, the findings are that older adults consistently perform more poorly than younger adults, even after the older participants were exposed to positive stereotypes of older people.

Because of the dramatic nature of the findings reported by Levy and Langer (1994), coupled with some cause for methodological concern, we sought to investigate the robustness of the culturebased explanation for age differences in memory performance. To do so, the following two groups were selected for comparison: Anglophone Canadians and Cantonese-speaking Chinese individuals, who had recently immigrated to Canada from Hong Kong (hereafter referred to as Chinese Canadians). These two groups were selected for study for a number of reasons. First, Englishspeaking Canadians are Western in their cultural orientation and hold the same generally negative stereotypes of aging as do Americans (Reker \& Wong, 1988). We might thus expect cognitive performance of the older Anglophone Canadians to be as adversely affected by negative views of aging as that of older U.S. adults. Second, the Chinese Canadians are similar to the mainland Chinese in their more positive views of aging. The Chinese in Hong Kong tend to hold their elderly in high esteem and abide by intergenerational relationships guided by concepts of filial piety (Ho, 1996). Older Chinese Canadians tend to take pride in their cultural heritage and believe that its having provided enduring moral principles over a 5,000 year span speaks to its superiority (Yang, 1986). Asian elderly in North America are eager to pass on traditional values (e.g., caring for family members) to their grandchildren (Wong, 1995; Wong \& Watt, 1991), and veneration of the elderly in the Chinese culture has been quite well documented (e.g., Logan, Bian, \& Bian, 1998; Nylan, 1996). Although there is some evidence that the degree of positive regard for older people may be waning (Chow, 1999), veneration of the elderly remains an indelible cultural belief among the ethnic Chinese in Taiwan (Hermalin, Ofstedal \& Chang, 1996), Singapore (Schwartz, 1994), 
mainland China (Levy \& Langer, 1994), and Hong Kong (Cheng, 1996; Fry, 1995), as well as among Chinese, Korean, and Japanese immigrants in North America (Sung, 1985; Ujimoto, Nishio, Wong, \& Lam, 1992). Thus, although Chinese Canadians from Hong Kong may be more westernized than mainland Chinese, there is reason to believe that their perceptions of aging are more positive than those of Anglo Canadians.

Some evidence suggests that younger Chinese individuals' sense of filial piety may lessen with acculturation, such that they may hold less positive views of aging relative to older Chinese adults. Whereas older Chinese immigrants tend to retain their traditional cultural values, younger Chinese immigrants are more likely to embrace Western cultural norms (Yu, 1983). We therefore limit our study to younger and older Chinese immigrants who have been in Canada for less than 5 years, a period sufficiently short to ensure that even the youngest participants have spent by far the largest portion of their years in the East.

In the present study, groups of younger and older Englishspeaking Canadians and Chinese Canadians were administered a battery of four nonverbal memory tests. The memory tests were selected to vary across dimensions expected to favor performance by the Chinese sample and thus to implicitly test the appropriateness of aggregating performance scores, as Levy and Langer did. Although the nature of the stimuli was not included as a factor in the study, the memory tests were selected to vary in terms of the nature of the stimuli utilized (i.e., simple line drawings to more complex figures) in order to be able to capture potentially different memory functions.

All study participants were also administered measures of selfconstrual and attitudes toward aging. If positive views of aging do indeed contribute to better memory performance in old age, then one would expect to observe different age-based patterns of performance for the Chinese Canadians than for the Anglophone Canadians. Following Levy and Langer (1994), we anticipated no significant differences between the Chinese Canadian age groups and, following many other studies (e.g., Craik \& Jennings, 1992), we anticipated substantial age differences for the nonimmigrant Canadians. In addition, we assessed attitudes toward aging and investigated whether positive views toward aging lead to better memory performance among older adults.

\section{Method}

\section{Participants}

Fifty-six younger adults (aged 19-28 years, $M=22.3$ ) and 48 older adults (aged 60 to 88 years, $M=70.1$ ) living in the Toronto area were recruited. (Summary age statistics for all four subject participant groups appear in Table 1.) The younger adujts were recruited from a participant pool of undergraduate students attending the University of Toronto, whereas the older adults were active, well-educated, community-dwelling volunteers recruited through local community centers and churches. Half the participants in both the younger and the older group were Englishspeaking Canadians and the other half were Cantonese-speaking Chinese individuals who had lived in Canada for less than 5 years $(M=2.7$ years and $M=2.6$ years for younger and older Chinese Canadians, respectively; $F<1$ ).

To the extent possible, every effort was made to match the two culturalgroup samples in terms of socioeducational dimensions. Virtually all the Chinese Canadians lived in relatively homogeneous ethnic communities, where Cantonese is the main language of communication and extended
Table 1

Demographic Information for Study Participants

\begin{tabular}{|c|c|c|c|c|c|}
\hline Culture & Age & $n$ & Education & $\begin{array}{l}\text { Health } \\
\text { ratings }\end{array}$ & $\begin{array}{l}\text { Vocabulary } \\
\text { score } \\
\text { (Shipley) }\end{array}$ \\
\hline \multicolumn{6}{|c|}{ Younger adults } \\
\hline Anglo Canadian & & 28 & & & \\
\hline$M$ & 22.50 & & 15.75 & 1.89 & 30.30 \\
\hline$S D$ & 3.00 & & 1.69 & 0.69 & 4.20 \\
\hline Chinese Canadian & & 28 & & & \\
\hline$M$ & 22.20 & & 15.25 & 2.07 & 34.60 \\
\hline$S D$ & 1.40 & & 1.14 & 0.66 & 3.60 \\
\hline \multicolumn{6}{|c|}{ Older Adults } \\
\hline Anglo Canadian & & 24 & & & \\
\hline$M$ & 70.70 & & 16.83 & 1.88 & 35.40 \\
\hline$S D$ & 4.70 & & 2.50 & 0.74 & 4.20 \\
\hline Chinese Canadian & & 24 & & & \\
\hline$M$ & 69.50 & & 16.85 & 2.13 & 36.00 \\
\hline$S D$ & 8.70 & & 1.93 & 0.76 & 2.00 \\
\hline
\end{tabular}

family living arrangements are common. In fact, 12 out of 24 older Chinese Canadian participants lived with their adult children and grandchildren. Of the younger participants, all but 2 Chinese Canadian and 2 Anglo Canadian adults lived at home with their families in private dwellings. In addition, relatively few younger adults in both cultural groups were married ( $7 \%$ for Anglo Canadians vs. $11 \%$ for Chinese Canadians), with the vast majority of them being single. As might be expected, the majority of older adults ( $83 \%$ in each cultural group) were married. The remaining older participants within each cultural group were evenly split between being single and widowed. Finally, all but 4 of the Anglo Canadian and 3 Chinese Canadian older adults were retired.

To participate, all individuals had to have at least some college-level education $(M=15.5$ years for younger adults and $M=16.8$ years for older adults), $F(1,100)=13.5, M S E=3.34, p<.0001$. In addition, they were preselected on the basis of rating their health as excellent, good, or fair on a 5-point scale (with $1=$ excellent, 2 = good, 3 = fair, $4=$ somewhat poor, and $5=$ poor). Neither age nor cultural effects on health ratings were found to be significant (see Table 1 for means). Hence, because of the extensive selection criteria imposed in the recruitment process, none of the participants dropped out or failed to complete the study.

Given that all Chinese participants in our study had recently relocated from Hong Kong to Canada, we sought to determine the extent to which they had become acculturated (i.e., psychologically and socially, in the sense of Berry, Poortinga, Segall, \& Dasen, 1992), to better gauge whether their basic cultural values had been preserved. Amongst the frequent conclusions of recent studies of Chinese culture is that it is "grouporiented" (e.g., Hsu, 1981) and that social relationships and roles, which have been characterized in the literature as collectivistic (e.g., Hofstede, 1980; Triandis, 1988), constitute the core of the self. By contrast, North Americans tend to be more individualistic, valuing uniqueness of the individual and emphasizing personal goals over those of the group (Triandis, 1988). Consistent with these notions, Markus and Kitayama (1991) have suggested that people raised in North America tend to hold an independent view of the self (termed interdependent self-construal), whereas those raised in Asia hold a more interdependent view of the self (termed interdependent self-construal). Comparisons of self-construal for the four Age $\times$ Cultural Groups were conducted to verify that the Anglophone and Chinese Canadians in the study did indeed hold differing views of the self.

To this end, Singelis' (1994) Self-Construal Scale (SCS) was administered, yielding two separate scores (one for independent self-construal and 
Table 2

Study Participants' Self-Construal Scale and View of Aging Scores

\begin{tabular}{|c|c|c|c|c|c|}
\hline \multirow[b]{2}{*}{ Culture } & \multicolumn{2}{|c|}{ Acculturation } & \multicolumn{3}{|c|}{ View of aging } \\
\hline & $\begin{array}{l}\text { Interdependent } \\
\text { self-construal }\end{array}$ & $\begin{array}{l}\text { Independent } \\
\text { self-construal }\end{array}$ & $\begin{array}{c}\text { Positive } \\
\text { view }\end{array}$ & $\begin{array}{l}\text { Internal- } \\
\text { external }\end{array}$ & Activity \\
\hline \multicolumn{6}{|c|}{ Younger adults } \\
\hline \multicolumn{6}{|c|}{ Anglo Canadian } \\
\hline$M$ & 4.68 & 4.99 & 0.57 & 0.78 & 0.01 \\
\hline$S D$ & 0.34 & 0.53 & 0.27 & 0.17 & 0.04 \\
\hline \multicolumn{6}{|c|}{ Chinese Canadian } \\
\hline$M$ & 5.14 & 4.78 & 0.69 & 0.72 & 0.01 \\
\hline$S D$ & 0.59 & 0.53 & 0.24 & 0.16 & 0.04 \\
\hline \multicolumn{6}{|c|}{ Older adults } \\
\hline \multicolumn{6}{|c|}{ Anglo Canadian } \\
\hline$M$ & 4.64 & 4.96 & 0.58 & 0.70 & 0.01 \\
\hline$S D$ & 0.60 & 0.80 & 0.21 & 0.17 & 0.04 \\
\hline \multicolumn{6}{|c|}{ Chinese Canadian } \\
\hline$M$ & 5.45 & 4.90 & 0.75 & 0.70 & 0.02 \\
\hline$S D$ & 0.59 & 0.54 & 0.26 & 0.23 & 0.06 \\
\hline
\end{tabular}

another for interdependent self-construal) for each participant. ${ }^{1}$ On the basis of prior findings in the literature, we expected the Chinese Canadian and Anglophone Canadian participants to exhibit significant differences on the interdependent SCS score, though not necessarily on the independent one. Although we expect the Chinese Canadians to retain their generally respectful attitude toward their elderly, the Chinese Canadian sample, by choosing to emigrate, have engaged in an act of significant independence. Furthermore, one might expect that through contact with Canadian culture, some degree of acculturation may have taken place.

As expected, and consistent with previous findings in the literature (e.g., Y. R. Chen, Brockner, \& Katz, 1998; Singelis \& Sharkey, 1995), the Chinese Canadian individuals had greater interdependent SCS scores than Anglophone Canadians ( $M=5.28$ vs. $M=4.66$, respectively), $F(1$, $100)=35.69, M S E=.29, p<.0001$. There was no main effect of age on the interdependent SCS scores $(M=4.91$ vs. $M=5.04$, for younger vs. older adults, respectively), $F(1,100)=1.53, M S E=.29, p>.20$, although there was a marginally significant interaction effect of age and culture, $F(1$, $100)=2.83, M S E=.29, p<.10$ ) (see Table 2 for scores by age and culture), suggesting a tendency among Chinese Canadians for older adults to have higher interdependent scores than younger adults. As was also expected, there was no significant effect of culture or age, or their interaction, in the independent SCS scores (see Table 2 for group scores).

Participants were given the Shipley Institute of Living Vocabulary Test (Shipley, 1946; see Table 1). As is often the case with relatively welleducated sample populations, older participants had higher vocabulary scores than younger participants ( $M=35.70$ vs. $M=32.40$, respectively), $F(1,100)=20.96, M S E=13.23, p<.0001$. However, we also obtained a significant main effect of culture (with Chinese Canadians performing better than Anglophone Canadians) $F(1,100)=11.95, M S E=13.23, p<$ .001 , that was moderated by a significant interaction of Age $\times$ Culture, $F(1,100)=7.06, M S E=13.23, p<.01$, on vocabulary scores. Further analysis revealed that the verbal scores were equivalent for all Age $\times$ Culture Groups, with the exception of younger Anglophone Canadians, who not only performed significantly worse than their older counterparts, $F(1,50)=19.77, M S E=17.51, p<.0001$, but worse than the younger Chinese Canadians as well, $F(1,54)=17.38, M S E=15.42, p<.0001$. Although the reason for the significant interaction on vocabulary scores is not immediately apparent, the critical tasks are nonverbal, thus this ability difference is unlikely to account for any of the memory test results in this experiment. $^{2}$

\section{Test Materials and Procedure}

The study was individually administered to participants in either Cantonese or English by research assistants who were both bilingual and bicultural. Remuneration consisted of course credit for younger participants, whereas older participants were compensated $\$ 10$ for their participation. Chinese Canadian participants were given both the verbal and written instructions for the study entirely in Cantonese, whereas Anglophone Canadians were provided with the equivalent instructions in English. The participants were informed that the purpose of the study was to investigate people's general abilities as well as their cultural beliefs and attitudes about social situations. They were then given a series of tasks in the following order:

1. Copying component of the Emergent Complex Figures Test (JonesGotman, 1986);

2. Visual Reproduction Test I (immediate test; Wechsler, 1987);

3. Figural Memory Test (Wechsler, 1987);

4. Visual Reproduction Test II (delayed test; Wechsler, 1987);

5. Demographic questionnaire assessing age, gender, health, and education levels;

6. Shipley Institute of Living Vocabulary Test (Shipley, 1946);

7. Self-Construal Scale (Singelis, 1994);

8. An open-ended question eliciting five words on aging as a measure of stereotyping; and

\footnotetext{
${ }^{1}$ Anglophone Canadian participants received all instructions in English, whereas Chinese Canadian participants were provided instructions in written Chinese (as used in Hong Kong for representing the Cantonese dialect). To ensure that no meanings were altered in translation, three different translators translated all study materials from English to Chinese, and three additional translators then back-translated, with any resulting differences resolved by discussion among the translation team. The final Chinese version of the study materials was then thoroughly checked by a faculty member at the University of Toronto, who is fluent in written and spoken English, Cantonese, and Mandarin.

${ }^{2}$ As further evidence of the lack of a significant relationship between vocabulary and memory scores, none of the correlations of the vocabulary scores with memory scores (from both composite and individual tests) was found to be statistically significant.
} 
9. Delayed recall component of the Emergent Complex Figures Test (Jones-Gotman, 1986).

After completing the study session, participants were debriefed, thanked for their participation, and dismissed.

\section{Dependent Measures}

Memory. The primary dependent measures of memory were assessed by four different memory tests: (a) immediate recall of geometric designs (Visual Reproduction I), (b) immediate recognition of abstract designs (Figural Memory), (c) delayed recall of geometric designs (Visual Reproduction II), and (d) delayed recall of a complex pictorial design (Emergent Complex Figures). These specific tests were selected to satisfy the criteria that they (a) assess explicit memory functions known to decline with age (e.g., recall, recognition of complex material), (b) are sensitive measures in detecting age effects (Lezak, 1995; Spreen \& Strauss, 1991), and (c) differ from the memory tests utilized by Levy and Langer (1994). Further, although all the tests were nonverbal to avoid potential confounding of memory performance with effects attributable to differences in language presentation, they varied in the nature of stimuli utilized, thereby enabling us to generalize across at least some memory functions.

The first three memory tests were taken from the Wechsler Memory Scale-Revised (WMS-R; Wechsler, 1987). The Visual Reproduction Test had two components: immediate (Part I) and delayed (Part II) recall trials. It consisted of four relatively simple geometric figure designs, of which three contained a single figure and the fourth contained a double figure with designs side by side. The participants were exposed to the designs for $10 \mathrm{~s}$ and then asked in a drawing-based test trial to depict what they remembered. The delayed recall trial was administered $10 \mathrm{~min}$ after the immediate recall trial.

During the 10-min interval between the two Visual Reproduction tests, individuals performed the Figural Memory Test, an immediate visual recognition test made up of four trials, each with one to three abstract rectangular designs in white and two shades of gray, set within squares of equal sizes. After the participant was shown the target designs, the stimuli were removed, and the participant was asked to identify the designs from an array of similar designs. The first trial involved just one design, which was shown for $5 \mathrm{~s}$, with three designs comprising the recognition set. The next three trials each displayed three similar designs for $15 \mathrm{~s}$, with an array of nine designs from which the participant had to try to identify the three just seen.

The Emergent Complex Figures Test (Jones-Gotman, 1986) assessed the delayed recall of a visually complex pictorial figure, for which an individual needs to impose an organized spatial structure in order to perform well on later recall. The complex figure was initially presented in a highly disorganized manner by asking participants to copy, step by step, on a single sheet of 8.5 -in. by 11-in. paper, each of the figure's 18 component elements, which were presented in an order predetermined by the experimenter. After the first element was shown, the remaining elements were revealed one at a time on 17 subsequent pages. Each page was shown for $10 \mathrm{~s}$, while participants copied each component. The presentation order was disorganized in the sense that the use of systematic processing strategies, which might serve in the construction and learning of the basic structure of the figure, was prevented. After a 45-min interval (during which they performed the other tasks in the study), participants were given a single sheet of 8.5 -in. by 11 -in. paper and were asked, without prior warning, to reproduce the figure from memory.

View of aging. To assess an individual's view of aging, we asked each participant to write down five words or phrases that came readily to mind when thinking of older people, in a manner similar to the method utilized by Levy and Langer (1994). The Anglophone Canadians responded in English whereas Chinese Canadians did so in Cantonese. The responses by the Chinese participants were rendered into English individually by two translators who were proficient in written and spoken Cantonese. Subsequently, two other individuals, who were unaware of the hypotheses or groupings (age, cultural) central to the study, rated each of the five words or phrases as positive (e.g., wise, knowledgeable), neutral (e.g., retired, telling stories), or negative (e.g., slow, senile) by scoring the responses as $1,0.5$, or 0 , respectively. The mean interrater reliability was $93 \%$, as measured by using the Spearman-Brown formula (Rosenthal \& Rosnow, 1991). Any differences in ratings between the raters were reconciled by discussion. For each participant, an overall measure of view toward aging (labeled a positive view score, ranging from 1 to 0 ) was computed by averaging across the assigned scores for the five descriptors.

Consistent with scoring by Levy and Langer (1994), the two judges also rated the descriptions on whether they signified an internal, as opposed to an external, dimension (interrater reliability $=.90$ ), and whether they were active or not active (interrater reliability $=.92$ ). Each description was coded as $\mathbf{1}$ if the characterization was internal (e.g., experienced, kind), .5 if it was neutral or not applicable to the item, and 0 if it was external in orientation (e.g., wrinkled, skinny). The coded ratings for the five descriptions were then averaged for each individual to assign an internal-external dimension score. In addition, each description was coded as 1 if it involved an active (e.g., exercise, travel) characterization or 0 for a nonactive (e.g., quiet, immobile) characterization. These coded ratings were similarly averaged to yield activity scores for each participant.

\section{Results}

\section{View of Aging}

Consistent with the Levy and Langer (1994) findings, Chinese individuals hold more positive views of aging than their North American counterparts (see Table 2 for means): Scores for positive view were significantly greater for the Chinese Canadians $(M=0.72)$ than for the Anglophone Canadians $(M=0.57), F(1$, $100)=9.58, M S E=0.06, p<.003$; no other effects were significant $(F \mathrm{~s}<1)$. However, contrary to findings reported by Levy and Langer (1994), none of the effects approached significance for either the internal-external or activity measures (see Table 2 for means).

\section{Memory}

Memory performance was initially assessed by analyzing the effects of age and culture on an overall memory score, which was created by combining the scores for the four collected memory measures in a manner similar to that of Levy and Langer (1994). As a first step, a correlation analysis of the four memory measures was performed. The correlation analysis yielded significant positive correlations for all component variables (see Table 3 ). To compare results using the best linearly weighted single memory measure with those based on its component memory test scores, we then performed a principal-components factor analysis. All four memory variables loaded relatively highly on a single factor,

Table 3

Correlations Between Performance on Memory Tests

\begin{tabular}{lllll}
\hline \multicolumn{1}{c}{ Memory tests } & 1 & 2 & 3 & 4 \\
\hline 1. Visual Reproduction I (immediate) & - & & & \\
2. Visual Reproduction II (delay) & .71 & - & & \\
3. Emergent Complex Figures & .45 & .55 & - & \\
4. Figural Memory & .32 & .48 & .39 & - \\
\hline
\end{tabular}

Note. All correlations are significant at $p<.01$. 
with factor weights $.79, .88, .78$, and .68 for immediate recall (Visual Reproduction I), delayed recall (Visual Reproduction II), delayed recall (Emergent Complex Figures), and immediate recognition (Figural Memory), respectively; results were qualitatively unaffected by varimax rotation. A memory score for each individual was then calculated as a factor-weighted average of the standardized scores for each of the four memory tests. The resultant individual memory scores ranged from -6.94 to 3.98 , with higher scores reflecting better overall performance. The means and standard deviations for the memory score by age and cultural group are presented in Table $4 .^{3}$

A two-way analysis of variance (ANOVA), with memory as the dependent variable, and culture and age as the independent variables, was then conducted (see Table 4 for group means). Consistent with the results of Levy and Langer (1994), the ANOVA revealed both significant main effects for age, $F(1,100)=108.91$, $M S E=2.20, p<.0001, \omega^{2}=.55$, and for culture, $F(1$, $100)=4.04, M S E=2.20, p<.04, \omega^{2}=.02$, and these main effects were qualified by a significant interaction effect, $F(1$, $100)=3.98, M S E=2.20, p<.05, \omega^{2}=.03 .{ }^{4}$ Simple effect tests were performed on the memory score in order to test specific predictions.

First, and most importantly, both Anglophone and Chinese Canadian younger adults were more accurate in their memory than older adults in their respective groups, $F(1,50)=88.85$, $M S E=2.30, p<.0001, \omega^{2}=.65$, for Anglophone Canadians; and $F(1,50)=38.76, M S E=2.90, p<.0001, \omega^{2}=.44$ for Chinese Canadians. However, although there was no significant difference in the memory scores between Anglophone Canadian and Chinese Canadian younger adults $(F<1)$, the Chinese Canadian older adults had higher memory scores than the Anglophone Canadian older adults, $F(1,46)=5.84, M S E=2.99, p<.02, \omega^{2}=.08$.

Hence, although the older Chinese Canadians did, in fact, perform better on the memory tasks than the older Anglophone Canadians, it is also true that, contrary to Levy and Langer's original findings, older Chinese Canadians performed significantly less well than younger Chinese Canadians.

We next replicated the prior analysis for each separate memory test; Table 5 lists means for each test, along with American norms (unavailable for Emergent Complex Figures; Jones-Gotman, personal communication, April 23, 1999). Interestingly, a different pattern of results emerged for the Visual Reproduction Tests as compared with the Figural Memory and Emergent Complex Figures tasks. Results of each of these analyses are discussed in turn. ${ }^{5}$

Visual Reproduction Test I: Immediate recall. As was found with the analysis of effects of age and culture on the composite memory score, the main effect of age group on the immediate recall version of the Visual Reproduction Test was significant, $F(1,100)=61.73, M S E=14.08, p<.0001, \omega^{2}=.38$. Likewise, the main effect of cultural group was significant, $F(1,100)=3.97$, $M S E=14.08, p<.05, \omega^{2}=.04$, with Chinese Canadian participants achieving higher scores than Anglophone Canadians. The two-way interaction of Age $\times$ Culture on the Visual Reproduction immediate recall scores was marginally significant, $F(1$, $100)=2.95, M S E=14.08, p<.10, \omega^{2}=.03$. A planned comparison test between the two older cultural groups further revealed a marginally significant difference, with the older Chinese Canadian participants outperforming the older Anglophone Canadian participants, $F(1,46)=3.70, M S E=22.37, p<.06$,
Table 4

Means of Combined Memory Score by Age and Culture

\begin{tabular}{lcc}
\hline & \multicolumn{2}{c}{ Culture } \\
\cline { 2 - 3 } Age & $\begin{array}{c}\text { Anglophone } \\
\text { Canadian }\end{array}$ & $\begin{array}{c}\text { Chinese } \\
\text { Canadian }\end{array}$ \\
\hline Younger & & \\
$M$ & 1.69 & 1.61 \\
$S D$ & 1.32 & 1.52 \\
Older & & \\
$M$ & -2.33 & -1.33 \\
$S D$ & 1.72 & 1.89 \\
\hline
\end{tabular}

Note. The individual scores for the memory variable range from -6.94 to 3.98 .

$\omega^{2}=.07$. No such significant difference in scores was found between the younger cultural groups $(F<1$ ). Moreover, both Anglophone and Chinese Canadian younger adults performed better on the immediate Visual Reproduction Test than their older counterparts, $F(1,50)=42.54, M S E=14.83, p<.0001$, $\omega^{2}=1.00$, for Anglophone Canadians; and $F(1,50)=20.61$, $M S E=13.34, p<.0001, \omega^{2}=.99$, for the Chinese Canadians. The overall results stemming from analysis of this memory test were therefore generally consistent with those found with the combined memory score.

Visual Reproduction Test II: Delayed recall. Analogous with the results obtained for the immediate recall version of the Visual Reproduction Test, the main effect of age was significant, as was the effect of culture, $F(1,100)=91.99, M S E=47.70, p<.0001$, $\omega^{2}=.48$, and $F(1,100)=6.98, M S E=47.70, p<.01, \omega^{2}=.07$, respectively. The interaction effect of Age $\times$ Culture for the delayed recall version was also significant, $F(1,100)=13.07$, $M S E=47.70, p<.0005, \omega^{2}=.12$, with both Anglophone and Chinese Canadian younger adults performing better on the delayed Visual Reproduction Test than their older counterparts, $F(1$, 50) $=96.32, M S E=43.19, p<.0001, \omega^{2}=.66$, for Anglophone Canadians; and $F(1,50)=16.31, M S E=52.20, p<.0002, \omega^{2}=$ .25 , for the Chinese Canadians. Whereas there was no significant difference in the scores for Anglophone and Chinese Canadian younger adults $(F<1)$, the Chinese Canadian older adults once again outperformed the Anglophone Canadian older adults on the delayed measure, $F(1,46)=12.87, M S E=67.38, p<.001$, $\omega^{2}=.22$.

\footnotetext{
${ }^{3}$ Because some evidence suggests that the Figural Memory Test may become nondiscriminating at the upper levels of the scale for persons 65 years and older (Lezak, 1995) all analyses involving composite memory measures were conducted, both including and excluding this measure. The main study results did not change when the Figural Memory score was excluded from the composite memory score for the analyses.

${ }^{4}$ Estimates of effect sizes are derived by calculating partial $\omega^{2}$ values (Hays, 1973; Keren \& Lewis, 1979). The partial $\omega^{2}$ statistic describes the proportion of total variability attributable to a particular factor or interaction among factors within a fixed effects model.

${ }^{5}$ All of the main analyses were also performed using $z$ scores as dependent measures. These analyses yielded the same results as are reported for the raw scores.
} 
Table 5

Mean Memory Scores by Age and Culture and American Norms

\begin{tabular}{|c|c|c|c|c|}
\hline Culture & $\begin{array}{c}\text { Visual } \\
\text { Reproduction I } \\
\text { (immediate) }\end{array}$ & $\begin{array}{c}\text { Visual } \\
\text { Reproduction II } \\
\text { (delay) }\end{array}$ & $\begin{array}{c}\text { Emergent } \\
\text { Complex } \\
\text { Figures }\end{array}$ & $\begin{array}{c}\text { Figural } \\
\text { Memory }\end{array}$ \\
\hline \multicolumn{5}{|c|}{ Younger adults } \\
\hline \multicolumn{5}{|c|}{ Anglophone Canadian } \\
\hline$M$ & 37.1 & 32.9 & 51.6 & 8.3 \\
\hline$S D$ & 2.6 & 4.2 & 14.4 & 1.3 \\
\hline \multicolumn{5}{|c|}{ Chinese Canadian } \\
\hline$M$ & 37.3 & 31.5 & 54.6 & 8.0 \\
\hline$S D$ & 2.4 & 6.6 & 17.6 & 1.1 \\
\hline \multicolumn{5}{|c|}{ Older adults } \\
\hline \multicolumn{5}{|c|}{ Anglophone Canadian } \\
\hline$M$ & 30.1 & 14.9 & 35.6 & 6.5 \\
\hline$S D$ & 4.2 & 8.5 & 11.9 & 1.9 \\
\hline \multicolumn{5}{|c|}{ Chinese Canadian } \\
\hline$M$ & 32.7 & 23.4 & 34.3 & 6.7 \\
\hline$S D$ & 4.3 & 7.9 & 15.4 & 1.4 \\
\hline \multicolumn{5}{|c|}{ Maximum Test Scores } \\
\hline & 41.0 & 41.0 & 100.0 & 10.0 \\
\hline \multicolumn{5}{|c|}{ American Norms } \\
\hline \multicolumn{5}{|l|}{ Ages $25-34$} \\
\hline$M$ & 34.5 & 32.8 & - & 7.2 \\
\hline$S D$ & 5.4 & 6.6 & & 1.5 \\
\hline \multicolumn{5}{|l|}{ Ages $75-95$} \\
\hline$M$ & 29.1 & 20.1 & - & 6.5 \\
\hline$S D$ & 7.3 & 9.1 & & 1.5 \\
\hline \multicolumn{5}{|l|}{ Ages $76-80$} \\
\hline$M$ & 28.2 & 16.1 & - & - \\
\hline$S D$ & 4.8 & 7.3 & & \\
\hline
\end{tabular}

Note. The norms for the younger adults, based on a sample considered representative of the 1980 U.S. census data, were obtained from Mittenberg, Burton, Darrow, and Thompson (1992). As would be expected by the wider age range and lower average education levels sampled, these norms for younger adults are somewhat lower than the scores we obtained for our own study participants. The norms for the 75- to 95 -year-old adults were reported by Cullum, Butters, Troster, and Salmon (1990) and were from healthy, community dwelling volunteers with an average of 14.5 years of education. Norms for 76 to 80 year olds were reported by Richardson and Marottoli (1996) for only the Visual Reproduction I and II tests and reflected data obtained from active, independent, and healthy older adults with over 12 years of education. We were unable to locate any sources for norms on the Emergent Complex Figures test and were informed by Jones-Gotman (personal communication, April 23, 1999) that they were unavailable.

Emergent Complex Figures Test: Delayed recall. Analysis of the responses from the Emergent Complex Figures Test, however, revealed a different pattern of results from those of the two Visual Reproduction Tests and from the memory score as well. For this measure, the only reliable effect was for age, $F(1,100)=37.54$, $M S E=227.30, p<.0001, \omega^{2}=.27$. Both Anglophone and Chinese Canadian younger adults performed better on the Emergent Complex Figures task than their older age mates, $F(1$, 50) $=18.51, M S E=178.00, p<.0001, \omega^{2}=.27$, for Anglophone Canadians; $F(1,50)=19.39, M S E=276.59, p<.0001, \omega^{2}=.28$ for Chinese Canadians. Neither the main effect of culture nor the interaction of Age $\times$ Culture approached significance $(F \mathrm{~s}<1)$, findings inconsistent with the memory score.

Figural Memory Test: Immediate recognition. The same contrary pattern of results that was found for the Emergent Complex Figures Test was obtained with analysis of data for the Figural
Memory Test. Only the main effect of age was significant, $F(1$, $100)=29.67, M S E=2.11, p<.0001, \omega^{2}=.23$. Moreover, both Anglophone and Chinese Canadian younger adults performed better on the Emergent Complex Figures task than their older counterparts, $F(1,50)=15.68, M S E=2.61, p<.0001, \omega^{2}=.24$, for Anglophone Canadians; $F(1,50)=14.12, M S E=1.63, p<$ $.0001, \omega^{2}=.22$, for Chinese Canadians. Neither the main effect of culture nor the interaction effect of Age $\times$ Culture was significant $(F \mathrm{~s}<1)$. These findings are also inconsistent with the memory score.

Summary. Separate analyses of the data deriving from each of the memory tests reveal a pattern of results different from what might be expected based on the combined memory score alone. In only two of the four memory tests, the immediate and delayed recall versions of the Visual Reproduction Test, do the older Chinese Canadian adults approach-but not achieve-the perfor- 


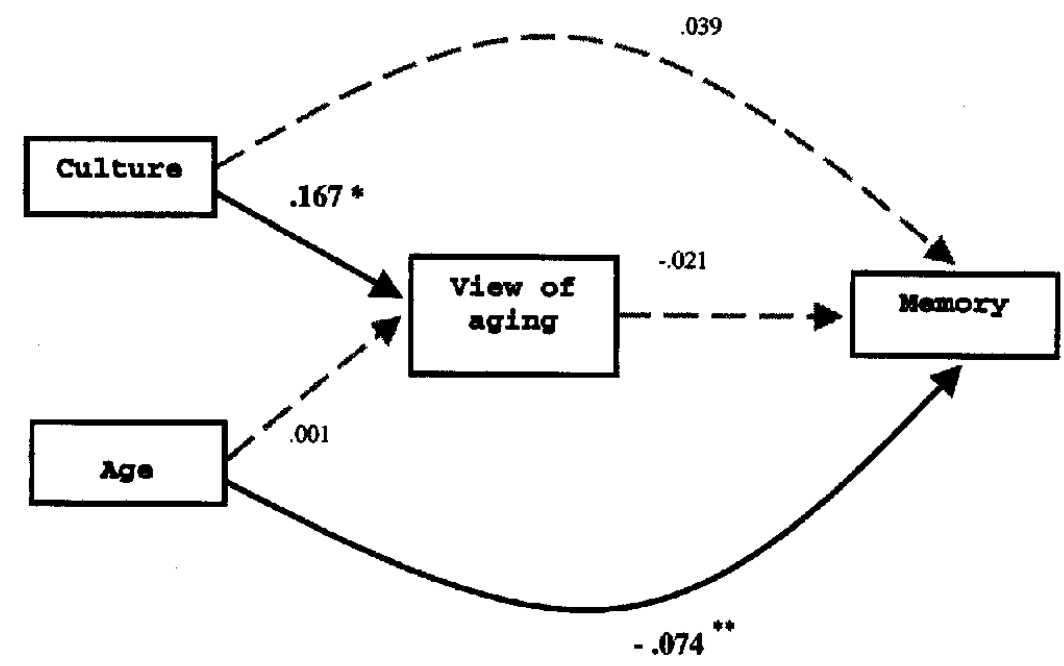

Figure 1. Path analysis for all study participants. The solid arrow indicates a significant path. ${ }^{*} p<$ $.01 . * * p<.001$.

mance of their younger counterparts and outperform the older Anglophone Canadian adults. The older Chinese Canadian adults perform as poorly on the Emergent Complex Figures and Figural Memory tasks as the older Anglophone Canadian adults. In contrast to the data of Levy and Langer (1994), younger adults outperform the older adults on all the memory tests in both cultural groups. It is intriguing that a pattern of results consistent with Levy and Langer's was obtained for the Visual Reproduction Tests (and not for the Emergent Complex Figures or Figural Memory). On the basis of the judgment of the translation panel and a bilingual graduate student not involved in the preparation of the study materials, it appears that of the three test types-Visual Reproduction, Figural Memory, and Emergent Complex Figures-the first bears a significant degree of resemblance to ideographic elements used in written Chinese. We might thus speculate that a differential advantage may accrue to the Chinese Canadian participants only on this test, if at all. Although nothing in the present study can claim to attribute the Levy and Langer results completely to such an enhanced sensitivity in the older Chinese sample, we believe this possibility merits future study.

\section{Relationship Between View of Aging and Memory}

To test the hypothesis that views of aging mediate memory performance, a path analysis was performed (see Figure 1 ), ${ }^{6}$ with positive view, memory, and age as continuous variables, and with culture as a dummy variable $(0=$ Canadian, $1=$ Chinese $)$. Contrary to Levy and Langer's findings, positive view and memory were not significantly correlated for either the younger or the older group. We further tested for the influence of culture on memory, with positive view as the mediator variable, finding that positive view did not function as a mediator. The only significant relationship obtained was the effect of culture on positive view of aging (coefficient $=.17, p<.001$ ). Our analysis yielded one additional significant coefficient, that associated with the direct path between age and memory, which was statistically significant in a negative direction (coefficient $=-.07, p<.0001$ ).
Given the results of the path analyses, it would be difficult to argue that the effect of age on memory is mediated by one's view of aging. In addition, although it is clear that membership in a cultural group influences a person's views on aging, the data do not support the existence of a relationship between culture and general memory, and there is not a mediational role played by one's view of aging within the relationship. These results, taken together with the equivocal results obtained from analysis of the separate memory measures, reveal a more complex pattern than can be attributed to a wholly culturally based account of age differences in explicit memory performance.

\section{Discussion}

The results of the present study are inconsistent with the notion that cultural stereotypes of aging account for age differences in memory performance. Several findings argue against this view.

First, younger adults always outperformed older adults. For all four separate memory measures, and for the derived memory score, there was a main effect of age. Such a set of effects argues rather forcefully that memory performance consistently differed between the younger and older adults in both cultural groups, in contrast with the results reported by Levy and Langer (1994). Interestingly, however, our data are consistent with those of Levy (1996), which, if pooled across the two experiments reported in that paper, revealed superior memory performance for younger adults compared with older adults on a variety of memory tests.

Second, the impact of culture emerged in only two of the four tests, the immediate and delayed versions of the Visual Reproduction Test, with effects far weaker than those of age. Although older Chinese Canadians did better on these two tests than did their Anglophone age mates, performance on the Emergent Complex

\footnotetext{
${ }^{6}$ Path analyses for both younger and older adults were also performed for each of the four memory tests separately. The patterns of results were found to be the same as that for the memory score.
} 
Figures and Figural Memory tests did not differ across culture for the older adults. Overall, then, there appeared to be limited evidence for a difference between the performance of the Chinese and Anglophone Canadian participants, coupled with effect size data suggesting a larger difference between the older and younger ones.

Hence, there was only mixed evidence of an advantage for older Chinese over older Anglophone Canadians. On only two of the tests (the immediate and delayed versions of the Visual Reproduction Test, the same ones for which main effects of culture were obtained) was the Age $\times$ Culture interaction significant. Therefore, even after accounting for the large differences between the older and younger adults' performances, evidence for enhanced performance on the part of the older Chinese Canadian participants is at best equivocal. The magnitude of these effects was, in any case, small enough to suggest that the moderating influence of culture was rather modest: Direct tests of performance differences between the older and younger Chinese Canadian adults indicated that this is the case, and although these differences were not as large as those between their Anglophone Canadian counterparts, they were significant for all the memory measures. Simply stated, if the five analyses were conducted only on the Chinese Canadian participants, then the unambiguous conclusion would be that there is a substantial age difference in performance. The sole support for the moderating effects of culture, then, would be that such age differences were smaller for Chinese than Anglophone Canadian participants on two of the tests.

It is difficult to explain the inconsistent pattern of results across the four different memory measures used in this study. Because the Levy and Langer (1994) study made use of a parsimonious "super memory" variable aggregated across test and memory types, it cannot be ascertained whether the superior memory performance reported for the older mainland Chinese adults in their study was obtained on all or just a subset of the memory tests. However, it is interesting to note that in our study, significant Age $\times$ Culture interactions were obtained with only the two memory tests utilizing the same test materials (Visual Reproduction I and Visual Reproduction II). We suggest that these two memory tests, on which the older Chinese Canadian participants excelled, called on the very type of memory, that for simple geometric figures, which is likely to be used daily in their ideographic written language. It is well known that, compared with alphabetic systems (as in nearly all Indo European languages) or syllabaries (as in Amharic or Cherokee), written languages that rely on mimetic representations of physical objects or abstract relations require a great deal of exposure in youth to master (C. Chen, 1996). Whereas a child who is learning the written form of a Romance, modern Semitic or Slavic language need merely come to grips with a few dozen symbols, one who is studying any of a number of Asian languages must not only become conversant with thousands of complex symbols, but learn to associate them with spoken sounds to which they are not phonetically related. Similar to chess masters who encode and retrieve realistic, though not random, configurations of pieces with far greater ease than novices (Chase \& Simon, 1973), it is possible that the Chinese Canadians were able to assimilate relatively simple figures to a significantly greater extent than Anglophone Canadians; by contrast, the cultural groups' performance levels were comparable for memory of spatial arrangements of geometrical objects, for which the ideographic writing system may offer at best modest advantages. In effect, then, the pattern of observed results is consistent with a rather different explanation for age-related deficits, one that has less to do with cultural views and more to do with differential abilities based on a lifetime of exposure to a complex mnemonic system.

One may be led to question why this differential ability in the visual reproduction tasks was not observed in a comparison between the two younger cultural groups. Although this question cannot be satisfactorily addressed in the context of the present study, we offer two plausible, interdependent, explanations for this. First, just as in the case of the vocabulary tests, where the differences between the better scoring older groups was not significant while that between the poorer scoring younger groups was, it is possible that this is essentially a ceiling effect (especially so for the immediate version of the Visual Reproduction test); the younger participants all performed so well relative to the maximum score (41) that ideographic familiarity was not especially advantageous. Second, it is possible that younger adults find this type of test to be relatively undemanding and that groupwise differences only emerge for tasks on which individuals are prone to err. However, we cannot rule out the possibility that the memory tests involved measures that tap some other latent constructs that differentially influenced the cultural groups across the lifespan. This is an important issue that deserves systematic investigation, as suggested in a recent paper by Park, Nisbett, and Hedden (1999). They raise the possibility that specific tasks may systematically favor performance of East Asian or Western individuals and argue the need for basic research that would allow cross-cultural researchers to distinguish between cognitive tasks that are culture free and culture saturated.

Finally, our conclusions regarding the benefits (or lack thereof) of cultural beliefs for memory performance are further supported by the results of the path analysis, conducted on both age groups. The only two significant effects were the effect leading from culture toward view of aging and the direct negative effect of age on memory performance. The path analysis therefore indicates that, aside from the strongly negative (main) effect of age on memory performance, all other effects are, in a real sense, nonsignificant.

In sum, on the basis of the results of the present study, we found culture to play no real explanatory role, whereas age played a decisive one, a conclusion supported by all relevant statistical measures across the set of memory tests employed. Although any null effects must necessarily be interpreted with caution, the overall pattern of results suggests that age-related stereotypes alone are unlikely to account for age-related differences in general memory performance. Nonetheless, it seems premature to reject the notion out of hand that cultural beliefs may moderate age differences. It is unlikely that a complete understanding of age-related memory differences will be possible without a clearer picture of the nature of social or cultural beliefs about memory across the lifespan. It is possible for a culture to venerate those who have achieved advanced age, while at the same time recognize certain physical or cognitive limitations that may accompany aging. Therefore, it could well be that accounting for cultural beliefs regarding effects of aging on memory, and not merely aging in general, would paint a richer portrait of the phenomenon under study. We therefore think it valuable to identify task- and domain-specific contexts in which social expectations and stereotypes may well differentially influence memory functions of older versus younger adults. The 
present findings, however, lend little support to the notion that cultural values about aging will necessarily buffer against the kinds of age-related memory deficits that are otherwise seen throughout the cognitive gerontology literature.

\section{References}

Albert, M., Jones, K., Savage, C., Berkman, L., Seeman, T., Blazer, D., \& Rowe, J. (1995). Predictors of cognitive change in older persons: MacAuthor studies of successful aging. Psychology and Aging, 10, 578-589.

Berry, J. W., Poortinga, Y. H., Segall, M. H., \& Dasen, P. R. (1992). Cross-cultural psychology: Research and applications. Cambridge, England: Cambridge University Press.

Cavanaugh, J. C. (1989). The importance of awareness in memory aging. In L. W. Poon, D. C. Rubin, \& B. A. Wilson (Eds.), Everyday cognition in adulthood and late life (pp. 416-436). Cambridge, England: Cambridge University Press.

Chase, W. G., \& Simon, H. A. (1973). Perceptions in chess. Cognitive Psychology, 4, 55-81.

Chen, H. C. (1996). Chinese reading and comprehension: A cognitive psychology perspective. In M. H. Bond (Ed.), The handbook of Chinese psychology (pp. 43-62). New York: Oxford University Press.

Chen, Y. R., Brockner, J., \& Katz, T. (1998). Toward an explanation of cultural differences in in-group favoritism: The role of individual versus collective primacy. Journal of Personality and Social Psychology, 75, $1490-1502$.

Cheng, C. H. K. (1996). Towards a culturally relevant model of selfconcept for the Hong Kong Chinese. In J. Pandey, D. Sinha, \& D. P. S. Bhawuk (Eds.), Asian contributions to cross-cultural psychology (pp. 235-254). New Delhi, India: Sage.

Chow, N. (1999). Diminishing fillial piety and the changing role and status of the elders in Hong Kong. Hallym International Journal of Aging, 1, 67-77.

Craik, F. I. M., \& Jennings, J. M. (1992). Human memory. In F. I. M. Craik \& T. A. Salthouse (Eds.), The handbook of aging and cognition (pp. 51-110). Hillsdale, NJ: Erlbaum.

Cullum, C., Butters, N., Troster, A., \& Salmon, D. (1990). Normal aging and forgetting rates on the Wechsler Memory Scale-Revised. Archives of Clinical Neuropsychology, 5, 23-30.

Erber, J. T. (1989). Young and older adults' appraisal of memory failures in young and older adult target persons. Journal of Gerontology: Psychological Sciences, 44, 170-175.

Fiske, A. P., Kitayama, S., Markus, H. R., \& Nisbett, R. E. (1998). The cultural matrix of social psychology. In D. Gilbert, S. Fiske, \& G. Lindzey (Eds.), Handbook of social psychology (4th ed., pp. 915-981). New York: Oxford University Press and McGraw-Hill.

Fry, C. L. (1995). Kinship and individuation: Cross-cultural perspectives on intergenerational relations. In V. L. Bengston, K. W. Schaie, \& L. Burton (Eds.), Adult intergenerational relations: Effects of societal change (pp. 126-156). New York: Springer.

Hays, W. L. (1973). Statistics for the social sciences. New York: Holt, Rinehart \& Winston.

Hermalin, A. I., Ofstedal, M. B., \& Chang, M. C. (1996). Types of supports for the aged and their providers in Taiwan. In T. K. Hareven (Ed.), Aging and generational relations: Life-course and cross-cultural perspectives (pp. 400-437). New York: W. de Gruyter.

Hertzog, C., Dixon, R. A., \& Hultsch, D. F. (1990). Relationships between metamemory, memory predictions, and memory task performance in adults. Psychology and Aging, 6, 215-227.

Ho, D. Y. F. (1996). Filial piety and its psychological consequences. In M. H. Bond (Ed.), The handbook of Chinese psychology (pp. 155-165). New York: Oxford University Press.

Hofstede, G. (1980). Culture's consequences: Intemational differences in work-related values. Beverly Hills, CA: Sage.
Hsu, F. L. K. (1981). American and Chinese: Passage to differences. Honolulu: University of Hawaii Press.

Jones-Gotman, M. (1986). Memory for designs: The hippocampal contribution. Neuropsychologia, 24, 193-203.

Kahn, R. L., Zarit, S. H., Hilbert, N. M., \& Niederehe, G. (1975). Memory complaint and impairment in the aged: The effect of depression and altered brain function. Archives of General Psychiatry, 32, 1569-1573.

Kausler, D. H. (1994). Learning and memory in normal aging. San Diego, CA: Academic Press.

Keren, G., \& Lewis, C. (1979). Partial omega squared for ANOVA designs. Educational and Psychological Measurement, 39, 119-128.

Lachman, M. E., Weaver, S. L., Bandura, M., Elliott, E., \& Lewkowicz, C. J. (1992). Improving memory and control beliefs through cognitive restructuring and self-generated strategies. Journal of Gerontology: Psychological Sciences, 47, 293-299.

Langer, E., Rodin, J., Beck, P., Weinman, C., \& Spitzer, L. (1979). Environmental determinants of memory improvement in late adulthood. Journal of Personality and Social Psychology, 37. 2003-2013.

Levy, B. (1996). Improving memory in old age through implicit selfstereotyping. Journal of Personality and Social Psychology, 71, 10921107.

Levy, B., \& Langer, E. (1994). Aging free from negative stereotypes: Successful memory in China and among the American deaf. Joumal of Personality and Social Psychology, 66, 989-997.

Lezak, M. D. (1995). Neuropsychological assessment. New York: Oxford University Press.

Logan, J. R., Bian, F., \& Bian, Y. (1998). Tradition and change in the urban Chinese family: The case of living arrangements. Social Forces, 76, 851-883.

Markus, H. R., \& Kitayama, S. (1991). Culture and the self: Implications for cognition, emotion, and motivation. Psychological Review, 98, 224253.

Mittenberg, W., Burton, D. B., Darrow, E., \& Thompson, G. B. (1992). Normative data for the Wechsler Memory Scale-Revised: 25- to 35year olds. Psychological Assessment, 4, 363-368.

Nylan, M. (1996). Confucian piety and individualism in Han China. The Journal of the American Oriental Society, 116, 1-28.

Park, D. C., Nisbett, R., \& Hedden, T. (1999). Aging, culture, and cognition. Journal of Gerontology: Psychological Sciences, 54B, P75-P84.

Pratt, W. B., \& Norris, J. E. (1994). The social psychology of aging. Cambridge, MA: Blackwell Publishers.

Reker, G. T., \& Wong, P. T. P. (1988). Aging as an individual process: Toward a theory of personal meaning. In J. E. Birren \& V. L. Bengtson (Eds.), Emergent theories of aging (pp. 214-246). New York: Springer.

Richardson, E. D., \& Marottoli, R. A. (1996). Education-specific normative data on common neuropsychological indices for individuals older than 75 years. The Clinical Neuropsychologist, 10, 375-381.

Rodin, J., \& Langer, E. (1980). Aging labels: The decline of control and the fall of self-esteem. Journal of Social 1ssues, 36, 12-39.

Rosenthal, R., \& Rosnow, R. (1991). Essentials of behavioral research: Methods and data analysis. New York: McGraw-Hill.

Ryan, E. B. (1992). Beliefs about memory changes across the adult lifespan. Journal of Gerontology: Psychological Sciences, 47, 41-46.

Ryan, E. B., \& Kwong-See, S. (1993). Age-based beliefs about memory changes for self and others across adulthood. Journal of Gerontology: Psychological Sciences, 48, 199-201.

Ryan, E. B., Kwong-See, S., Meneer, W. B., \& Trovato, D. (1992). Age-based perceptions of language performance among younger and older adults. Communication Research, 19, 311-331.

Schwartz, S. H. (1994). Cultural dimensions of values: Toward an understanding of national differences. In U. Kim, H. C. Triandis, C. Kagitcibasi, S. C. Choi, \& G. Yoon (Eds.), Individualism and collectivism: Theory, method, and application (pp. 85-119). Thousand Oaks, CA: Sage. 
Scogin, F., Storandt, M., \& Lott, L. (1985). Memory-skills training, memory complaints, and depression in older adults. Joumal of Gerontology, 40, 562-568.

Shipley, W. C. (1946). Institute of Living Scale. Los Angeles: Western Psychological Services.

Singelis, T. M. (1994). The measurement of independent and interdependent self-construals. Society for Personality and Social Psychology, 20 , 580-591.

Singelis, T. M., \& Sharkey, W. F. (1995). Culture, self-construal, and embarassability. Joumal of Cross-Cultural Psychology, 26, 622-644.

Spreen, O., \& Strauss, E. (1991). A compendium of neuropsychological tests: Administration, norms, and commentary. New York: Oxford University Press.

Sung, B. L. (1985). Bicultural conflicts in Chinese immigrant children. Journal of Comparative Family Studies, 16, 255-269.

Triandis, H. (1988). Collectivism v. individualism: A reconceptualisation of a basic concept in cross-cultural social psychology. In G. K. Verma \& C. Bagley (Eds.), Cross-cultural studies of personality, attitudes, and cognition (pp. 60-95). London: MacMillan Press.

Ujimoto, K. V., Nishio, H. K., Wong, P. T. P., \& Lam, L. (1992). Cultural factors affecting the self-assessment of health satisfaction. In R. Masi, L. Mensah, \& K. McLeod (Eds.), Health and cultures: Explaining the relationships (pp. 229-240). Toronto: Canadian Council of Multicultural Health.

Wechsler, D. (1987). Wechsler Memory Scale--Revised Manual. San Antonio, TX: The Psychological Corporation.

Wong, P. T. P. (1995). The adaptive processes of reminiscence. In B Haight \& J. D. Webster (Eds.), Reminiscence: Theory, research meth ods, and applications (pp. 23-35). Washington, DC: Taylor \& Francis.

Wong, P. T. P., \& Watt, L. M. (1991). What type of reminiscence are associated with successful aging? Psychology and Aging, 6, 272-279.

Yang, K. S. (1986). Chinese personality and its change. In M. H. Bond (Ed.), The psychology of the Chinese people (pp. 106-170). Hong Kong: Oxford University Press.

Yu, L. C. (1983). Patterns of fillial belief and behavior within the contemporary Chinese American family. International Journal of Sociology of the Family, 13, 17-36.

Zacks, R. T., Hasher, L., \& Li, K. Z. H. L. (1999). Human memory. In F. I. M. Craik \& T. A. Salthouse (Eds.), Handbook of aging and cognition (2nd ed., pp. 293-357). Mahwah, NJ: Erlbaum.

Received June 22, 1999

Revision received May 12, 2000

Accepted May 12, 2000 